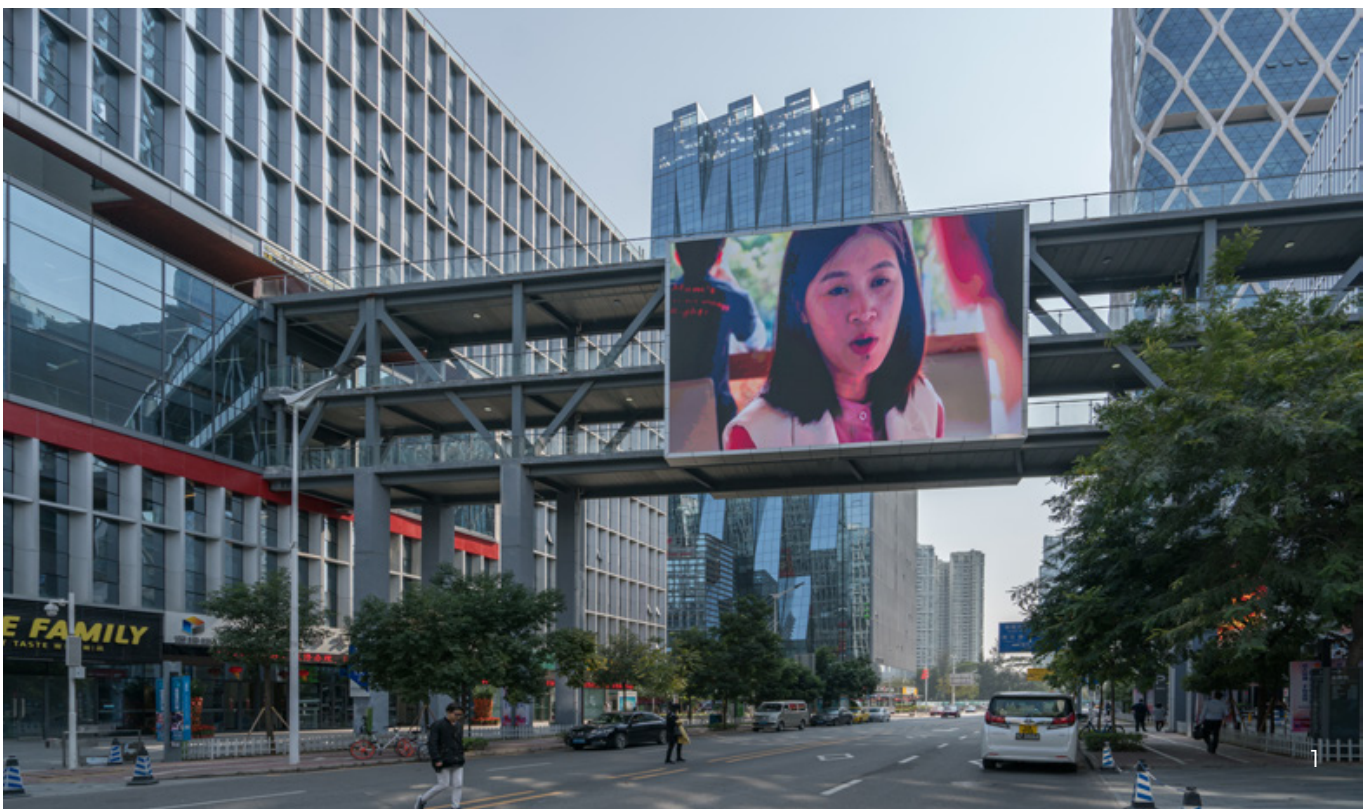

\section{Futures and Ruins \\ The Politics, Aesthetics, and Temporality of Infrastructure}

Tong LAM

In both the socialist and post-socialist eras, many of China's infrastructure projects took place in the so-called special zones or areas that were designated respectively for war preparation as well as economic and technological development. These large-scale infrastructure projects have made promises about the future, but have also left behind a trail of ruins and foreclosed possibilities. Amid these utopian and dystopian landscapes are opportunities to reflect on China's relentless development and our growing planetary crisis.
One of the many clean, orderly, and technooriented high-tech parks built in Shenzhen's former farmlands. Enclaves such as this also determine the amenities, land values, as well as who get to work and live in the area. PC: Tong Lam. uture and ruin are two intricately linked concepts. Especially in the age of a growing planetary crisis, conceptualising the future often anticipates ruination whereas ruins are symbols of abandoned futures. Nowhere is this paradox manifested more profoundly than in China's recent frenetic development. In less than four decades, China has transformed from a predominately agrarian society to an urban one. The rapid pace of urbanisation is especially visible in the nation's relentless urban renewal projects, the rise of instant cities, and more recently, the building of 'smart cities' and science parks. Meanwhile, intricately linked to this process is also a growing collection of modern ruins, including the so-called 'ghost 
cities' sensationalised by the media, as well as the little-known rustbelt cities in the hinterlands.

My ongoing project is a genealogy of special zones from China's Cold War secret cities to post-socialist smart cities. In the contemporary era, science parks and smart cities are specific kinds of special zone that use techno-science as the cultural trope and physical marker to present themselves as visions of the future. But shared characteristics aside, the stories collected from my interviews, ethnographic observations, and archival research reveal that the developmental trajectories of these zones were often products of contingent events, improvised experiments, as well as local and national politics. For example, while the history of the Zhongguancun Science Park in Beijing and the Shenzhen Special Economic Zone are both central to the understanding of China's post-socialist development-including the issues of urbanism, state-led neoliberalism, and the so-called Chinese developmental modelthey hardly shared the same historical path or the same imagined future. Therefore, even though the existence of both places was briefly called into question immediately after the 1989 Tiananmen uprising, and while they are now both dubbed China's 'Silicon Valley', the recent histories and present conditions of these two sites cannot be more dissimilar. Nonetheless, together, they tell the complicated and behindthe-scenes stories of China's high-speed growth and the underlying economic logics of its rising geopolitical ambitions. Among the stories I have collected, for instance, are the practices of how the Chinese state has tried to export its model of special zones to friendly countries of the Global South.

In this respect, the proliferation of these special zones as tropes, territorial spaces, financial speculation, and governmental technologies should be considered along with parallel developments elsewhere. Likewise, the ruination of these spaces-from foreclosure to abandonment-is also a global process. Therefore, even if the phenomenon of Chinese ghost cities may look extreme, such cities are far from unique. In fact, arguably, these places are concrete stories of ruination and of the planetary crisis in the age of the Anthropocene and Capitalocene (Moore 2015, 1-13)

The evolution and the rise and fall of special zones in contemporary China is only one part of my project, however. After all, these special zones are also preceded by another kind of special zone developed in the midtwentieth century during the socialist Cold War mobilisation. Indeed, in China at least, the concept of the special zone was introduced in the 1950s and proliferated massively in the 1960s. Starting in 1964, specifically, China began to see the development of a wave of what could be called 'instant factory towns'. Commonly known as the Third Front Construction, the decade-long mobilisation was an intense effort in developing industrial-based settlements as part of China's preparation for a possible full-scale war, including a nuclear war, with the Soviet Union and the United States. It is little surprise then that when special economic zones such as Shenzhen and Zhuhai were introduced in the late 1970s, they too were articulated in the logics of emergence and exception. However, unlike the socialist secret cities, these special zones were launched with different underlying ideology, political economy, and aesthetic considerations. Unsurprisingly, as new investments were redirected to newly-established special zones along the coast, many factory towns built primarily for war preparation during the Cold War era also began to fall into ruins. Thus, just as there are plenty of capitalist industrial rustbelt cities, there also exist many Chinese socialist rustbelt cities (Lam 2019).

In the following, I would like to use a few images to further contemplate the issues of temporality, aesthetics, and politics of infrastructure in the context of special zones. To begin with, infrastructure projects have clear implications for social justice, rights, as well as social inclusion and exclusion, even though they are often presented as apolitical and non-ideological. More precisely, unlike human rights, the rights to infrastructure 
are frequently determined by technocrats and experts (Mitchell 2002). And even when debates about infrastructure do take place in public discourse, it seems that the promises made by infrastructural projects are also about erasing all controversies and alternatives by putting them into a black box. For example, there may be endless controversies about the construction of a particular high-speed train station, but once it is built, it becomes an inevitability. In this regard, the enormity of infrastructure forecloses possibilities as much as creating new ones.

In a similar fashion, since infrastructure is often used to articulate political promises, it seems that the distinction between infrastructure and ruins should be obvious. The former points to development, social betterment, and the future; the latter represents failure, disinvestment, and abandonment. In short, they evoke opposite emotions and senses. In reality, however, these two supposedly distinct temporalities often collapse into one another. Take, for instance, the case of Shenzhen's Huaqiangbei neighbourhood. The area's old factory buildings house a large number of small workshops and hackerspaces for product design and development. These places-whether their activities are considered imitation or innovation-represent the heart and soul of Huaqiangbei's reputation as the world largest market for electronic accessories. But do these old factories represent images of aging or even crumbling infrastructure? Or, are these forward-looking examples of reuse and rehabilitation?

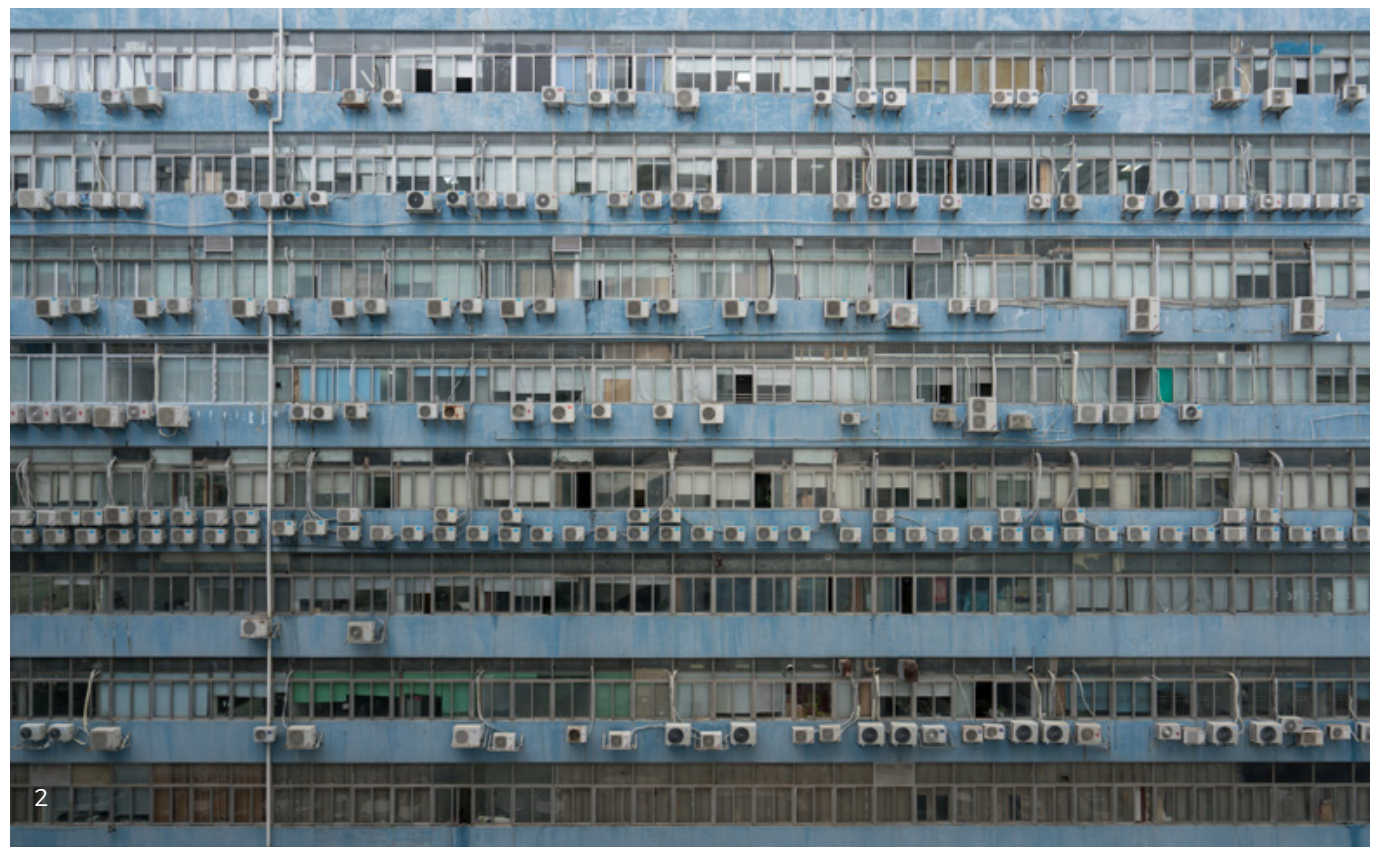

(2) A former factory in Shenzhen's Huaqiangbei district. Once upon a time, these air-conditioning units were symbols of modernity. As Shenzhen's Huaqiangbei is being rebranded as a place for innovation and entrepreneurship rather than production, many industrial buildings built in the 1990s such as this have also been updated with a futuristic look. PC: Tong Lam. 

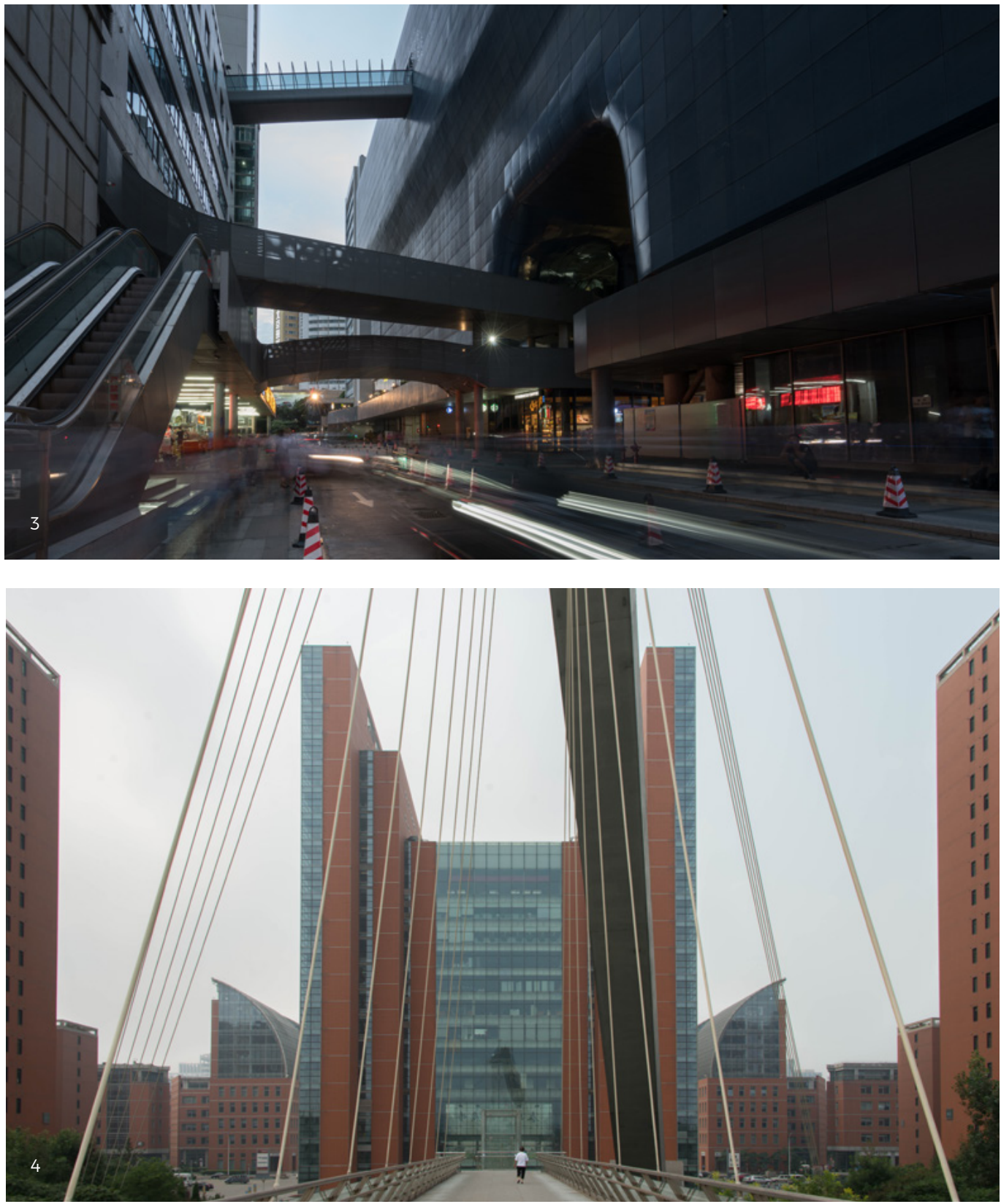

(3) An old factory from the 1990s in Shenzhen's Huaqiangbei with a newly-installed façade.

(4) This newly-built instant city in the suburb of Tianjin has been branded as a science park. Yet, like many similar places elsewhere in China, they have remained mostly empty so far and are sometimes being referred to as 'ghost cities' by the media. Still, this place has been used as a model by the Chinese government for promoting and exporting the practice of the science park to some friendly countries of the Global South. PC: Tong Lam. 


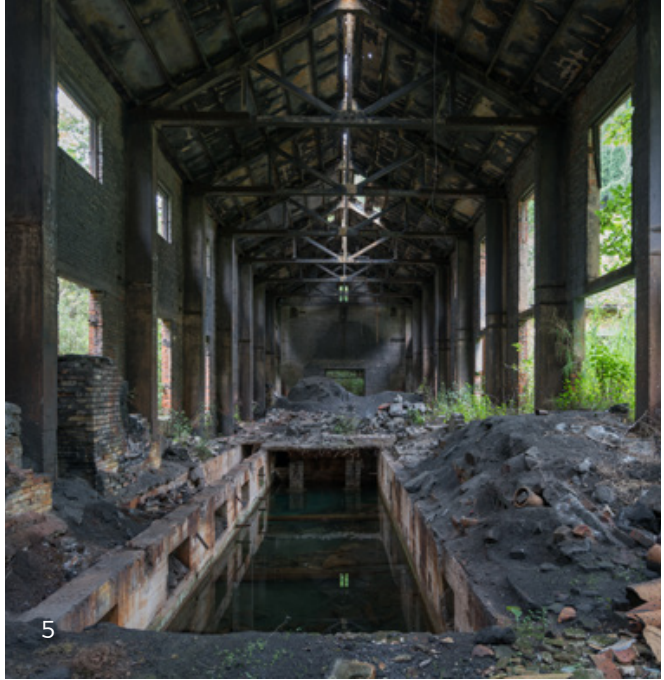

(5) An abandoned military factory in one of the former secret cities in Guizhou province. During the Third Front Construction that began in 1964 . hundreds of these instant factory towns were built in southwestern China. However, as industries migrated back to the coastal area after the 1980s, many of these places have become China's rustbelt cites. PC: Tong Lam.

After all, such flexible use of space is one of the basic conditions for Huaqiangbei's success. And since the public discourse on infrastructure is often more about visible structures and objects, rather than underlying facilities and networks, no wonder some landlords in Huaqiangbei have begun to repackage their old buildings with futuristic facades even though the interior spaces and functions of these updated buildings stay the same, i.e., as warehouses, workshops, makerspaces, and retail spaces.

In other words, aesthetics and the senses seem to play a crucial role in our perception of infrastructure (and ruins) in the contemporary visual and sensorial economy. As such, images are not superficial or false, as Guy Debord (1994) contends in his thesis, The Society of the Spectacle. Rather, they are part of the infrastructure. Moreover, scholars of science

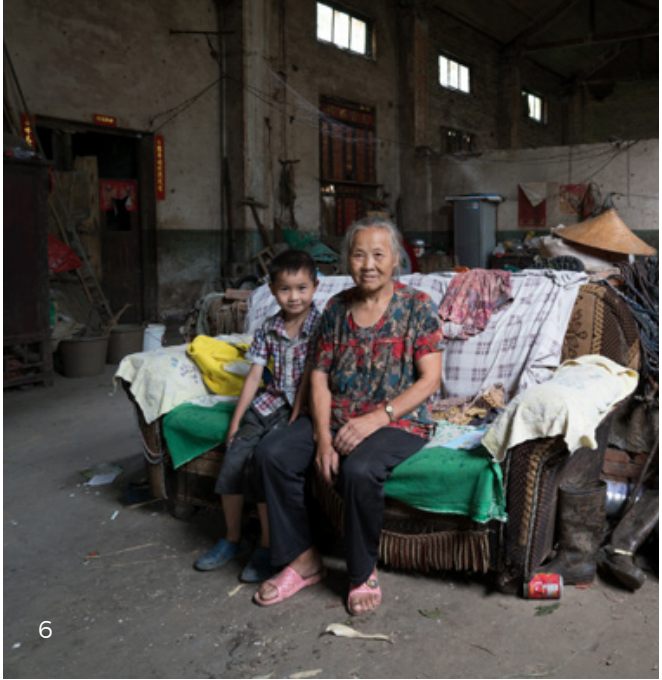

(6) Peasants squatting an abandoned factory in a former special zone in Guizhou province. Ruins. in other words, do not just involved dilapidated infrastructure and unused spaces, but also the ruination of lives and abandonment of people. Put differently, if smart cities with their capacity to collect data and modify human behaviour. abandoned rustbelt cities are places where the state choose to neglect. PC: Tong Lam.

and technology studies have long noticed the importance of culture in the forms of narrative, trust, and sentiment in the production of scientific knowledge (Latour 1987; Shapin 1994). They have also argued that the networks of actors and institutions are pivotal to the constitution of admissible data and evidence, the implementation of scientific experiments, and the persuasiveness of arguments. In the same vein, infrastructure-including materiality and the emotions associated with it-is a main force that makes the special zone's techno-scientific claims and promises about the future persuasive.

Meanwhile, the paradoxical relationship between infrastructure and ruins can be seen in a variety of contexts. This is especially the case in China where many newly-constructed cities and districts have remained unoccupied and have begun to fall into ruins due to 


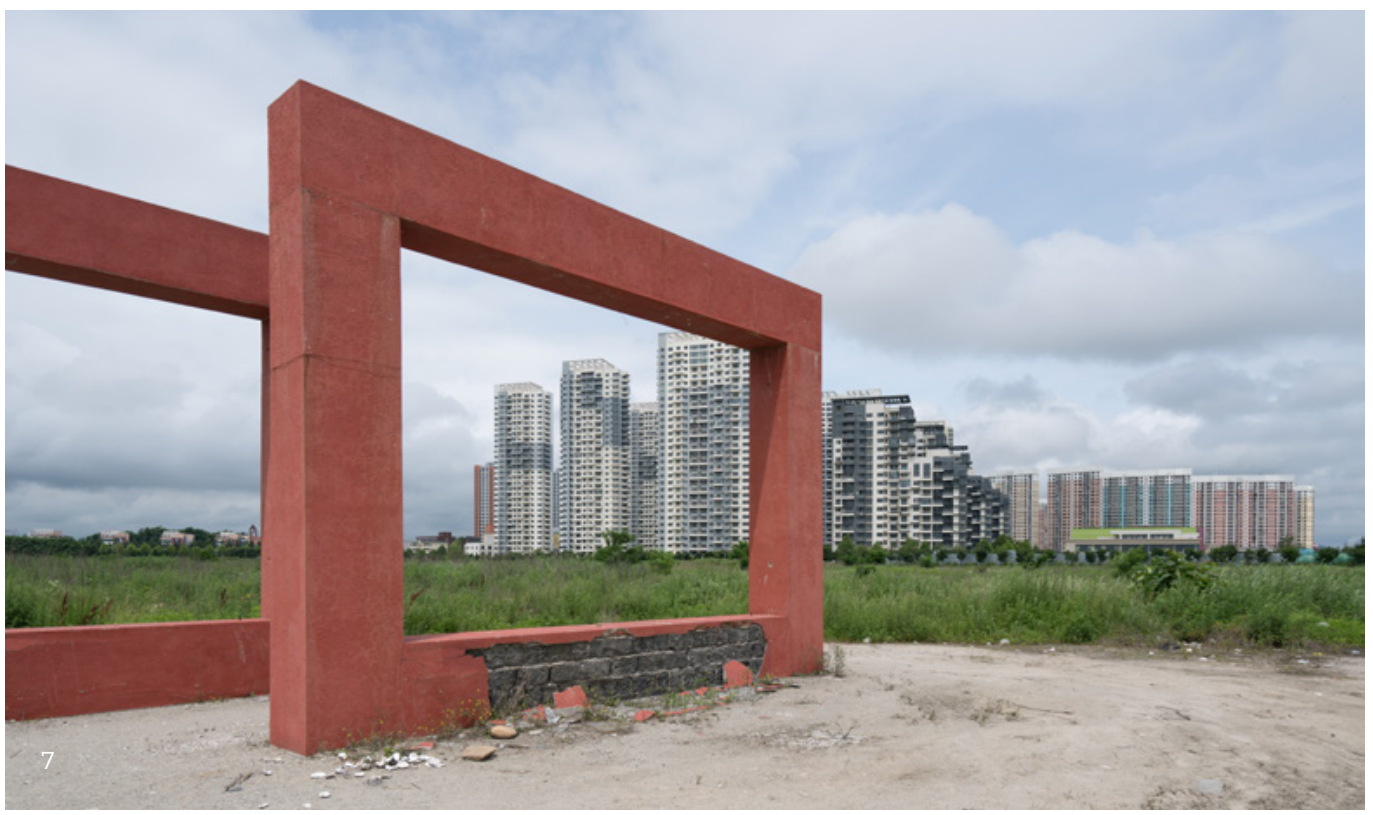

(7) Mostly driven by speculation, this new district in Dandong has remained unoccupied and has even begun to fall into ruin. PC: Tong Lam.

overdevelopment. But unlike ancient ruins that often convey a sense of historical sublime, modern ruins are about untimely death. And the sound of silence echoing within the spaces of these abandoned buildings does not inspire the excitement of a grand future, but the melancholy of abandoned dreams.

Still, in spite of their dilapidation and demise, ruins always outlast us, not so much as permanently preserved heritage but as debris and dust. Ultimately, as Walter Benjamin $(2008,180)$ puts it, ruins in the realm of things are similar to allegories in the realm of thoughts. In other words, like allegories, ruins are inherently unstable, and they allude to possibilities and missed opportunities. As such, ruins as cultural tropes and political allegories are productive for contemplating questions of civilisation, violence, and destruction. If so, perhaps it would be no less revealing to think about the question of human civilisation through ruins of new infrastructure in our growing planetary crisis. 